\title{
SYNCHROTRON XRF ANALYSES OF ELEMENT DISTRIBUTION IN FOSSILIZED SAUROPOD DINOSAUR BONES
}

\author{
M. Dumont ${ }^{1}$, N. Zoeger ${ }^{2}$, C. Streli ${ }^{2}$, P. Wobrauschek ${ }^{2}$, \\ G. Falkenberg ${ }^{3}$, P.M. Sander ${ }^{4}$, A.R. Pyzalla ${ }^{1}$ \\ ${ }^{1}$ Max-Planck-Institut für Eisenforschung GmbH, Max-Planck-Straße 1, D-40237 Düsseldorf, \\ Germany \\ ${ }^{2}$ Atomic Institute of the Austrian Universities, Stadionallee 2, A-1020 Wien, Austria \\ ${ }^{3}$ Hamburger Synchrotronstrahlungslabor HASYLAB at the Deutschen Elektronen-Synchrotron, \\ DESY, Notkestrasse 85, D-22603 Hamburg, Germany \\ ${ }^{4}$ University of Bonn, Institute of Palaeontology, Nussallee, D-53115 Bonn, Germany
}

\begin{abstract}
Sauropod dinosaurs were typically one magnitude larger than any other living or extinct terrestrial animal. This sheer size of the sauropod leads to scale effects in their biology and physiology that still are inadequately understood. The only remnants of the sauropods are their fossilized bones. These fossilized bones have sustained burial for some hundred million years and thus may have experienced significant diagenetic changes. These diagenetic changes often do not affect bone preservation on the histological level, but may lead to significant alterations of the bone microstructure. Here the influence of diagenesis on the microstructure of fossilized sauropod bones using femur cross-section of Brachiosaurus brancai that was excavated in the Tendaguru beds in Tanzania is investigated. The element distribution in this dinosaur bone is studied by a combination of micro-X-ray-fluorescence ( $\mu$-XRF) using synchrotron radiation and energy dispersive X-ray analyses (EDX) in the scanning electron microscope. These techniques reveal quantitative values of the element concentration at a macroscopic level combined with qualitative information at high spatial resolution of the distribution of $\mathrm{Ca}, \mathrm{Co}, \mathrm{Cr}, \mathrm{V}, \mathrm{Pb}, \mathrm{U}, \mathrm{Sr}, \mathrm{Y}$, and As in the fossil bones. This allows a differentiation between the remnants of the original bone apatite and pore filling minerals and also a visualization of damage, e.g. cracks introduced by diagenetic processes.
\end{abstract}

\section{INTRODUCTION}

Fossilized bones are the only remnants of sauropod dinosaur cadavers that are available today to provide information about their organism. Diagenesis [1], which is the alteration of the bone that appears during burial and fossilization, may affect bone histology, bone porosity, protein content, the crystallinity of the bone apatite, carbonate content, and the bone's content of chemical species in general. The extent of diagenesis mainly depends on direct environmental conditions such as groundwater and sediment composition, soil hydrology and $\mathrm{pH}$, redox potential and temperature, mechanical pressure, biological factors, and particle transport [2].

During bone fossilization apatite replaces the structural protein collagen. The new apatite is incorporated into the bone by external $\mathrm{Ca}$ and $\mathrm{P}$, which are transported into the bone via diffusion processes [3]. While $\mu \mathrm{m}$-scale structures of the bone often appear well preserved, early diagenetic pseudomorphosis of bone apatite crystallites can impede the recovery of in-vivo compositional, trace element, and isotope data from fossil bone $[4,5]$.

Different experimental approaches have been applied to studying and identifying diagenetic processes [6]. Chemical analyses and atomic absorption spectroscopy allow the determination of 
$\mathrm{Sr}$ and $\mathrm{Ba}$ [7], but they have the disadvantages of being destructive and offering at best a coarse spatial resolution. Electron probe micro-analyses offer a spatial resolution in the $\mu \mathrm{m}$ and sub- $\mu \mathrm{m}$ range, but suffer from low sensitivity for elements such as $\mathrm{Sr}, \mathrm{U}, \mathrm{Ba}$, and $\mathrm{Zn}$, which are often encountered in fossilized bones [6, 8]. X-ray micro-fluorescence $(\mu-X R F)$ analyses are nondestructive. They allow semi-quantitative mapping of elements $(Z>14)$ with a local resolution in the order of some $\mu \mathrm{m}$ (depending on the X-ray optics in use) and have been frequently used for studies of archaeological bones [9]. While most research on diagenetic effects on bone has been conducted on archaeological bones, which typically are fully mineralised, here the elemental distribution is investigated in fossil sauropod dinosaurs buried roughly 140-150 millions years ago [10]. Using energy dispersive X-ray analyses in the SEM and $\mu-X R F$, the distribution of chemical elements in the fossilized bones is studied with high local resolution. The aim of the combination of these methods is an assessment of the diagenetic effects in sauropod long bones both on a macroscopic and a microscopic scale.

\section{EXPERIMENTAL}

\section{Sampling}

This investigation focuses on sauropod long bones, mainly because they have an exceedingly simple morphology that is largely the product of appositional growth [11] and also because they are by far the most abundant in the famed Tendaguru sauropod fauna from Africa from Upper Jurassic [10], which today is housed in the Museum für Naturkunde of the Humboldt-Universität Berlin NHUB [12-15]. 15mm diameter cores were drilled from the narrowest part of the diaphysis with details provided in [11]. Afterwards the cores were cut in half along their longitudinal axis. The specimens obtained are half-cylinders that cover the whole bone cortex from the cancellous bone in the center to the primary fibrolamellar bone on the outside. For the analyses, the half core was grinded using SiC paper, polished using diamond paste $(1 \mu \mathrm{m}$ size $)$ on felt plate. The sample was then cleaned with alcohol.

We started our analysis of the element composition of the sauropod fossil bones by choosing a core taken from specimen no. BrXV, which is a left femur of Brachiosaurus brancai, $219 \mathrm{~cm}$ in length [13], excavated from the Tendaguru beds. Based on palaeohistological studies [11], the femur BrXV belonged to an individual that was still growing. Figure 1 gives an overview of this long bone cortex. The area investigated is located in the white part, between the cancellous bone and the periosteal bone. In this area, the Haversian system, lamellae, and canaliculi appear well preserved (Figure 1.c)

\section{Energy Dispersive X-ray Analyses in the Scanning Electron Microscope (SEM-EDX)}

SEM/EDX investigations were carried out on Philips XL30 tungsten filament electron microscope operating at $15 \mathrm{kV}$ and equipped with EDAX EDS system. The EDX-analyses were performed on uncoated samples. After the EDX-analyses a thin gold layer was sputtered onto the sample surface in order to improve the quality of the secondary electron (SE) and the backscattered electron images (BSE). The element distribution maps obtained by EDX in the SEM reveal the element distribution in a qualitative way: the brighter an area appears in a map for a specific element, the higher is the element concentration.

\section{Synchrotron Micro-X-ray Fluorescence Analysis ( $\mu$-XRF)}

Synchrotron radiation induced micro-X-ray fluorescence analysis (SR- $\mu-X R F$ ) in confocal geometry was carried out at the micro focus end-station at HASYLAB, beamline L, Hamburg, 
Germany [16]. The primary X-ray beam was monochromatized at $17 \mathrm{keV}$ by a Ni/C multilayer monochromator and focused by a polycapillary half-lens onto the sample. A second polycapillary half-lens was installed in front of a silicon drift detector (SDD) in order to realize the confocal measurement geometry. By overlapping the focal spots of the two X-ray optic elements a well defined micro-volume was achieved from which the fluorescence radiation was detected. Scanning a $4 \mu \mathrm{m}$ thick $\mathrm{Au}$ foil and a $4 \mu \mathrm{m}$ wire, the detection volume at an energy of the Au-L $\alpha$ line $(9.7 \mathrm{keV})$ was determined to be $20 \times 14 \times 22 \mu \mathrm{m}^{3}$ (lateral $\mathrm{x}$ height $\mathrm{x}$ depth). In the present experiment the 3D capabilities of confocal SR- $\mu$ XRF were exploited to inhibit unwanted contribution of deeper sample layers (sample thickness $\sim 5 \mathrm{~mm}$ ) to the X-ray fluorescence spectra. In order to enable a comparison of the XRF results with data from the other imaging techniques a confocal $\mu$-XRF area scan was performed in the first layer of the sample. Fluorescence spectra were recorded at $68 \times 46$ pixels using a step-size of $10 \mu \mathrm{m}$ in each direction and a counting time of 5s per pixel. Net intensities for each pixel were obtained by AXIL fitting (AXIL Tools in QXAS version by IAEA, [17]) and normalization to $100 \mathrm{~mA}$ ring current and correction for detector dead time. Element maps were generated by converting the intensity data to 8-bit grayscale images using a scaling from 0 (black) to the maximum counts (white) for each detected element.
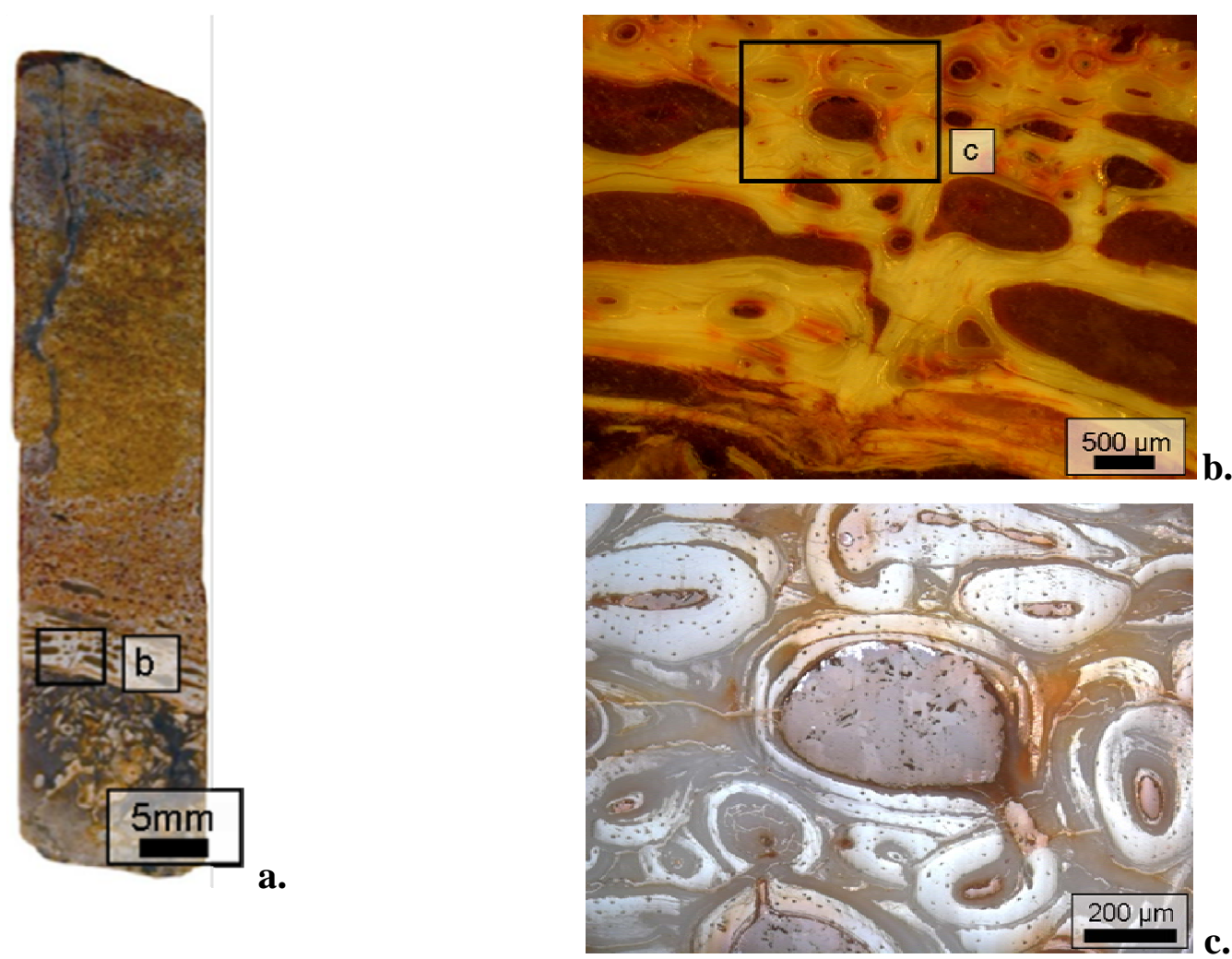

Figure 1: Optical micrographs of the sample (BrXV, Brachiosaurus brancai, mature individual, femur, femur length $219 \mathrm{~cm}$ ) a. Overview of the bone cortex. b.,c. Closer view of the area of interest 


\section{RESULTS}

\section{EDX Analysis in the Scanning Electron Microscope.}

The topographic features visible in the scanning electron microscope (SEM) image are visible also in the EDX maps of $\mathrm{Ca}, \mathrm{C}, \mathrm{Mg}, \mathrm{Na}, \mathrm{P}, \mathrm{Si}$, and $\mathrm{O}$ (Figure 2) The vascular canal contains a higher $\mathrm{Ca}, \mathrm{C}$, and $\mathrm{O}$ concentration than the fossil bone tissue (the bone tissue originally consisted of hydroxyapatite $\left.\mathrm{Ca}_{10}\left(\mathrm{PO}_{4}\right)_{6}(\mathrm{OH})_{2}\right)$. It reveals the presence of calcium carbonate $\mathrm{CaCO}_{3}$ in the vascular canal.

In contrast, the fossil bone apatite contains more $\mathrm{P}, \mathrm{Si}, \mathrm{Mg}$, and $\mathrm{Na}$ than the vascular canal. Since $\mathrm{P}$ was not detected in the calcium carbonate, the $\mathrm{P}$ distribution reveals very clearly the remnants of the apatite. Thus, the dark areas in the P EDX map reveal details such as cracks introduced by diagenetic processes, e.g. in the lamellae surrounding the vascular canal.
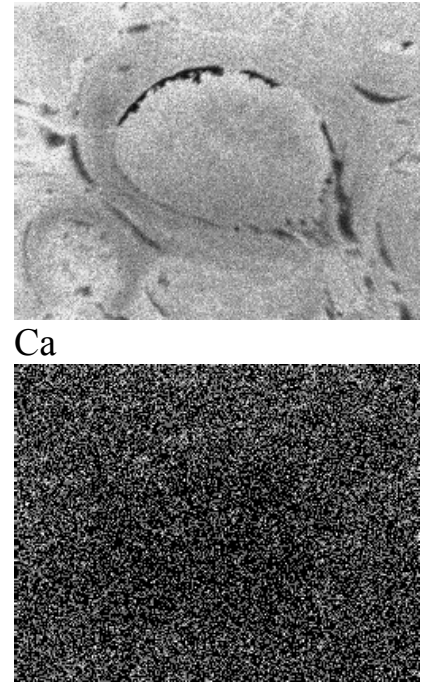

$\mathrm{Cu}$

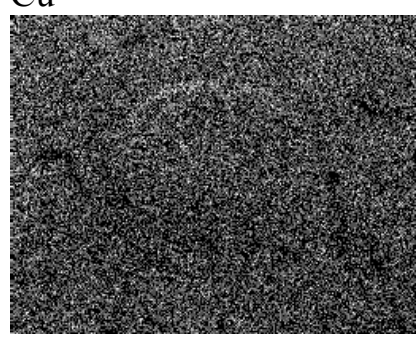

$\mathrm{Mn}$

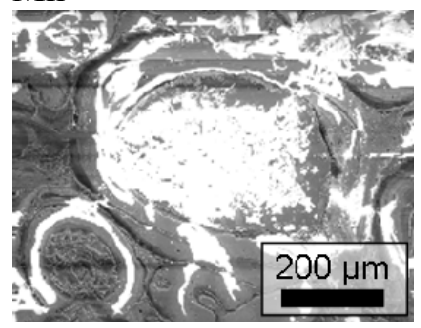

SE image (uncoated)

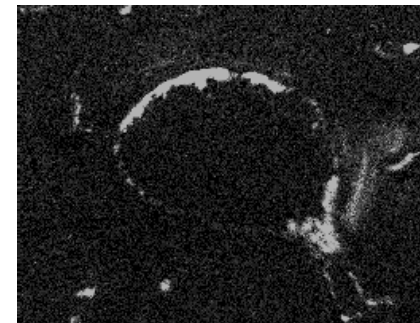

$\mathrm{Fe}$

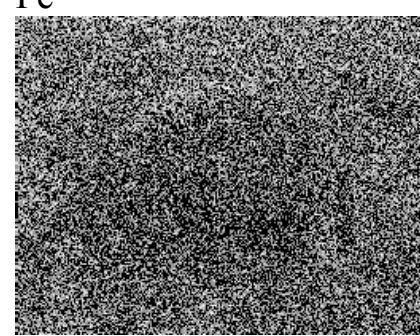

$\mathrm{Ni}$

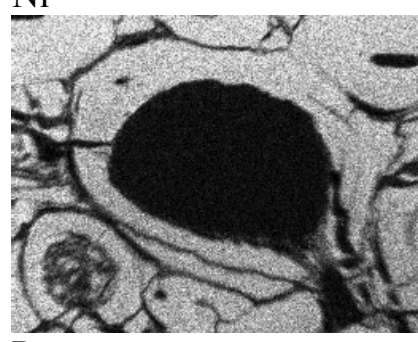

$\mathrm{P}$

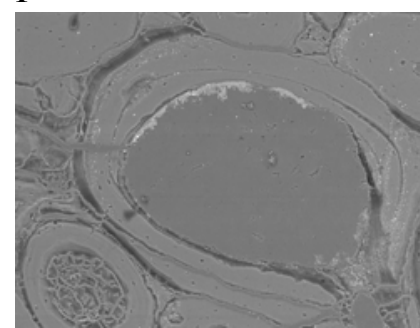

SE image (Au-coated)

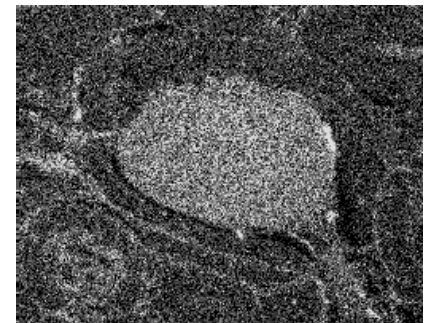

$\mathrm{C}$

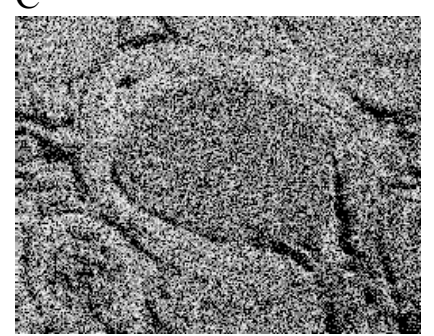

$\mathrm{Na}$

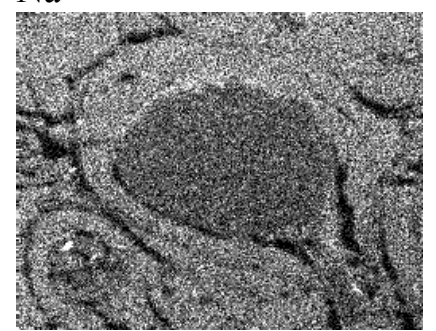

$\mathrm{Si}$

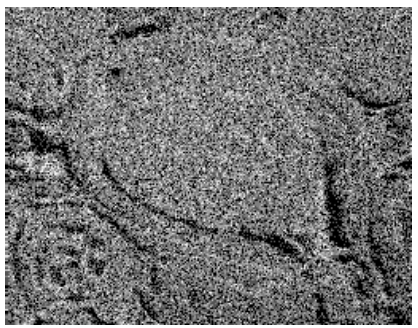

$\mathrm{Mg}$

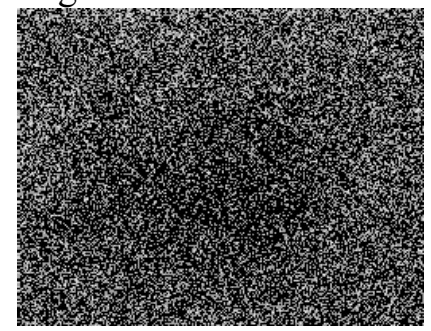

$\mathrm{Zn}$

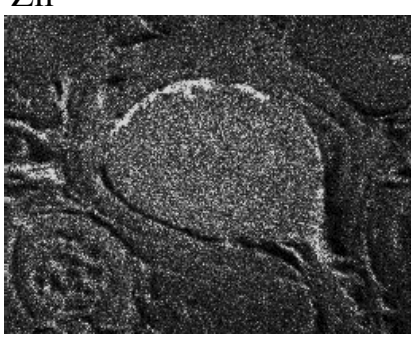

$\mathrm{O}$

Figure 2: SEM EDX element distribution maps of area of interest.

Comparing the $\mathrm{P}, \mathrm{Ca}$ and $\mathrm{Fe}$ EDX-maps reveals Fe enrichment at the interface between the vascular canal and the former apatite. In these areas with high iron content, both $\mathrm{Ca}$ and $\mathrm{P}$ 
contents are low. The Fe enrichment is accompanied by a substantial $\mathrm{O}$ enrichment, revealing the formation of iron oxides in these spaces. Also the $\mathrm{Si}, \mathrm{Mn}$, and $\mathrm{Ni}$ contents are higher in these regions than within the calcium carbonate and the formed apatite.

\section{SR- $\mu$ - X-ray Fluorescence Analysis (SR- $\mu-X R F)$}

The element distribution maps obtained with high spatial resolution using synchrotron radiation $\mu$-XRF similar to the EDX-analyses in the SEM reveal a qualitative image of the element distribution (Figure 3). For each element a scaling was performed with respect to the minimum and the maximum intensities obtained in the spectra collected over the sampled area. The dark areas in the plots for each element correspond to regions where we measured low XRF intensities, on the contrary an increasing brightness corresponds to higher intensities in the XRF spectra and thus to an enrichment in the respective element. Besides element distribution maps obtained for $\mathrm{Ca}, \mathrm{Fe}, \mathrm{Cu}, \mathrm{Ni}, \mathrm{Zn}$, and $\mathrm{Mn}$, where SEM EDX maps could be measured, $\mu-\mathrm{XRF}$ maps were determined for $\mathrm{Co}, \mathrm{Cr}, \mathrm{V}, \mathrm{Pb}, \mathrm{U}, \mathrm{Sr}, \mathrm{Y}$, and As.

Even more clearly than the EDX maps the $\mu$-XRF maps show the Ca distribution and thus the localization of the calcium carbonate within the vascular canal of the bone, in the cracks and between different lamellae surrounding the vascular canal. The calcium carbonate in addition to $\mathrm{Ca}, \mathrm{C}$, and $\mathrm{O}$ only contains $\mathrm{Mn}$ and a low amount of Sr.

Compared to the calcium carbonate the former apatite contains a significantly higher $\mathrm{Sr}$ concentration. The $\mu$-XRF distribution map of $\mathrm{Sr}$ in the former apatite compares well with the $\mathrm{U}$ distribution. The $\mathrm{Zn}$ distribution in the former apatite also appears similar to the $\mathrm{Sr}$ and $\mathrm{U}$ distribution. In both the $\mathrm{U}$ and the $\mathrm{Sr}$ map the calcium carbonate filled crack and the calcium carbonate filled rims between the lamellae are visible, which were also observed in the SEM EDX-maps.

$\mathrm{Fe}, \mathrm{Co}, \mathrm{Cr}, \mathrm{Cu}, \mathrm{Ni}, \mathrm{V}, \mathrm{Zn}, \mathrm{Mn}, \mathrm{Pb}$, and As show relative maximum values in the same locations at the interface between the calcium carbonate and the former apatite. The local maximum values of the Fe concentration determined by $\mu$-XRF coincide with those determined by SEM - EDX. 

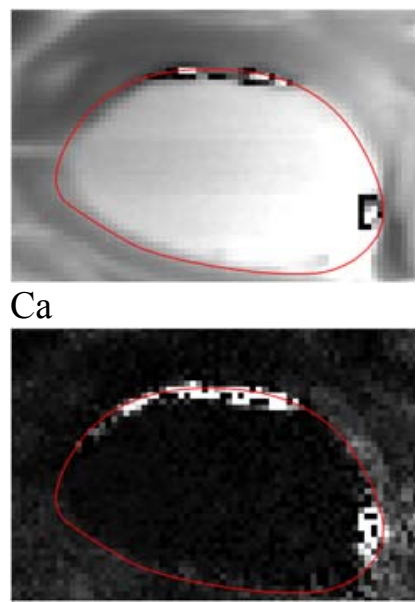

$\mathrm{Cu}$

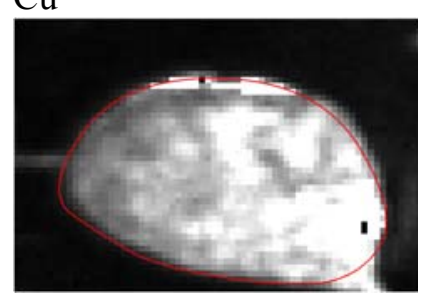

$\mathrm{Mn}$

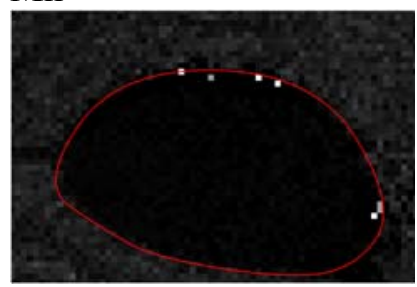

Y

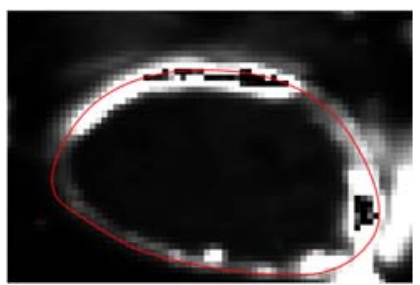

$\mathrm{Fe}$

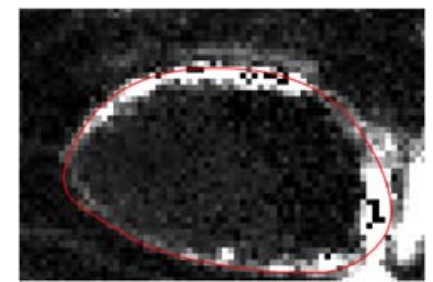

$\mathrm{Ni}$

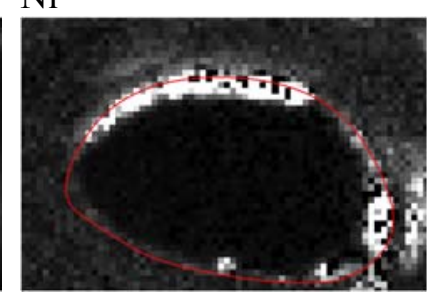

$\mathrm{Pb}$

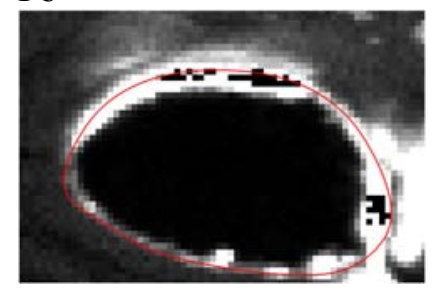

As

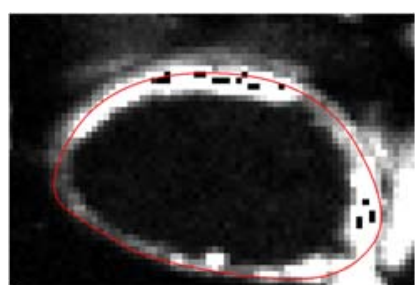

Co

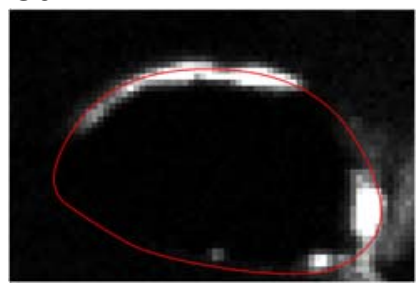

V

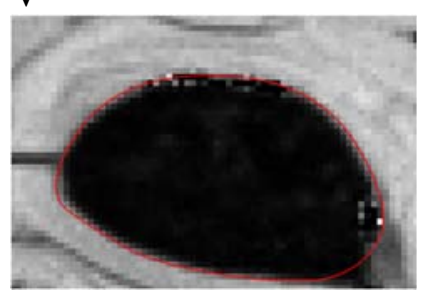

$\mathrm{U}$

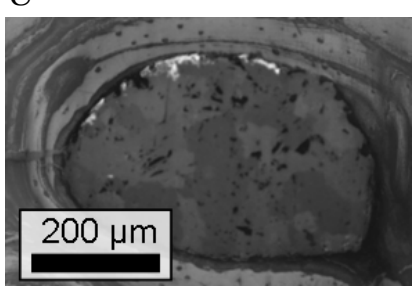

SE image

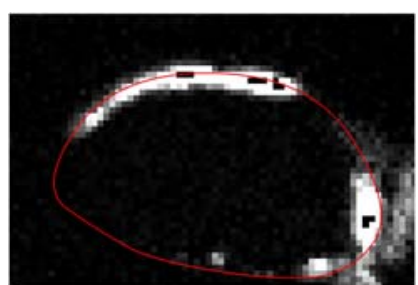

$\mathrm{Cr}$

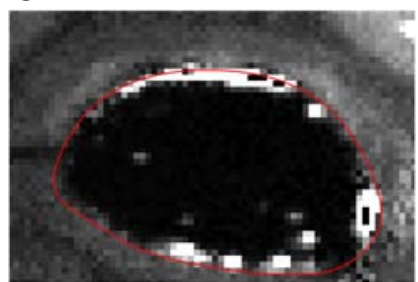

$\mathrm{Zn}$

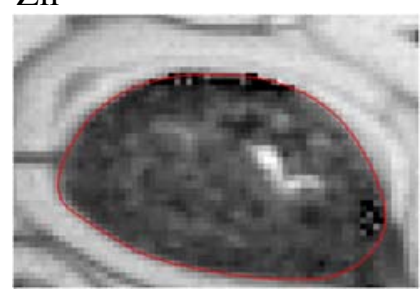

$\mathrm{Sr}$

Figure 3: $\mu$-XRF element distribution maps of area of interest.

\section{DISCUSSION}

\section{EDX Analysis in the SEM}

This technique is a fast and far more easily accessible tool for semi-quantitative analyses $(\mathrm{C}, \mathrm{O}$ and other light elements cannot be quantified reliably. However, this drawback can be overcome using WDX-analysis in a microprobe SEM) at the sample surface. By mapping the X-ray intensity of various chemical elements, their distribution can be related to the fossil microstructure. The EDX-maps of the $\mathrm{P}$ distribution directly reveal radial micro-cracks in the lamellae of the former vascular canals. The formation of radial micro-cracks can be attributed to diagenetic processes [18]. The micro-cracks form early during diagenesis due to internal stresses during the replacement of collagen by apatite [3]. The radial micro-cracks according to [19,3] have an important role during the diagenetic process, since they open additional pathways for diffusion in the Haversian bone and thus they contribute significantly to recrystallization and crystal growth of the former hydroxyapatite in the bone. In addition to radial micro-cracks, polygonal crack networks are also visible in the EDX-map of the element P. These polygonal cracks supposedly appear later during the diagenetic process due to external pressure on the fossil [3]. 


\section{Synchrotron $\mu$-XRF Analysis}

Synchrotron $\mu$-XRF analysis was first applied for the characterization of the element distribution in fossil bones. It provides a map of the element distribution with a spatial resolution comparable to those offered by EDX in the SEM, but due to its higher detection level in the order of a few ppm, the distribution of elements such as $\mathrm{U}, \mathrm{Sr}, \mathrm{Pb}$, and As can be determined, which are of particular interest for dietary indicators [20-23]. Compared to XRF using laboratory X-ray sources [24] synchrotron $\mu$-XRF provides a substantially higher spatial resolution and lower detection limits (in the range of $\mathrm{ng} / \mathrm{g}$ ). The combination of synchrotron XRF analyses with EDX analyses in the SEM provides a very clear differentiation between original and diageneticallyformed apatite and pore-filling minerals such as calcium carbonate or iron oxides, because $\mathrm{P}$ as well as $\mathrm{U}$ and $\mathrm{Sr}$ as minerals with an affinity to bone are almost exclusively present in the apatite.

\section{Element Distribution in Sauropod Dinosaur Bones}

A comparison of the element concentrations in the sauropod bone fossils basically indicates agreement with earlier investigations on archaeological bones [25,2], showing that $\mathrm{Ca}, \mathrm{Na}, \mathrm{K}$, and $\mathrm{Pb}$ are lower in the excavated samples (they leach out) and Fe, Mn, and $\mathrm{Al}$ are enriched in the excavated samples.

Except for $\mathrm{Fe}$, on a macroscopic level the distribution of elements in the sauropod bone investigated appears fairly homogeneous.

$\mathrm{Fe}, \mathrm{Mn}$ : Compared to modern bone, the fossilized sauropod femur shows a significantly higher Fe and Mn content. Both the SEM-EDX and the $\mu$-XRF element maps show that Fe and Mn apparently have a very similar spatial distribution, and a similar correlation of Fe and Mn was shown by PIXE microprobe investigations of archaeological human bones [26]. Elliott et al. [6] found Mn concentrated within the bone in patterns that correspond to the bone's small pore and canaliculi structures while Fe more typically filled the larger pores in the bone matrix such as Haversian canals. The combined occurrence of $\mathrm{Fe}, \mathrm{Mn}, \mathrm{Cr}, \mathrm{V}, \mathrm{Si}$, and $\mathrm{O}$ in the fossilized sauropod bones reveals that an oxide seam formed at the interface between the vascular canals and the former hydroxyapatite. Mn, besides being incorporated into the oxides, is known as a contaminant of the calcium carbonate from soil solution [27].

Enrichment of $\mathrm{Fe}$ in fossil bones has been observed previously by [25,1]. The distribution of Fe, which mainly covers the inner surface of the voids created by the degeneration of organic parts, might indicate that the iron oxides formed at an early stage of the diagenetic process.

$\mathrm{Sr}, \mathrm{U}: \mathrm{Sr}$ and $\mathrm{U}$ are two elements incorporated in the hydroxyapatite. Sr substitutes $\mathrm{Ca}$ in hydroxyapatite [20] and thus is mainly present in the fossilized former hydroxyapatite, but not exclusively present as earlier reported by [21]. $U$ is incorporated into the bone as complexes of the Uranyl ion by diffusion and subsequent adsorption [28]. The U decrease towards the medullar cavity might indicate that part of it leached out during the diagenetic process.

$\mathrm{Mg}$, Na: Light chemical species such as $\mathrm{Mg}$ and $\mathrm{Na}$ appear to be homogeneously distributed within the fossilised bone in contrast to previous studies on archaeological bones where $\mathrm{Mg}$ and $\mathrm{Na}$ were shown to leach out of the bone [20,2]. This homogeneous distribution is attributed to the long time available for diffusion.

$\mathrm{Ca}$ : According to [1], in the presence of calcium carbonate the $\mathrm{pH}$ of the bones is controlled by the $\mathrm{pH}$ of the waters entering the bone, which in turn prevents the dahllite from being dissolved. Thus the incorporation of large amounts of calcium carbonate in the sauropod fossil bones is an indication that most of the original apatite has been conserved. 


\section{CONCLUSIONS}

$\mu$-X-ray fluorescence analyses using synchrotron radiation determined the preferential location of elements within the sauropod fossils. The analyses allowed a qualitative determination of the element distribution on the level of a few $100 \mu^{2}$. Additional EDX analyses in the SEM provided information about the distribution of lower $\mathrm{Z}$ elements.

The combination of the different analysis techniques revealed that although seemingly unaffected at the histological level, the sauropod fossils endured strong diagenetic changes. Element maps of P obtained by SEM and element maps of Sr and $U$ obtained by $\mu$-XRF reveal the location of the remnants of the sauropod bone and show micro-cracks introduced by diagenesis. Both methods show that diagenetic minerals filled these micro-cracks and also the vascular canals of the bones. The concentration and distribution of the trace elements in the sauropod bones reveals that even in case of these extraordinary large fossils strong diagenetic changes occurred, which render conclusions about the abundance of trace elements in the living bones of sauropods extremely difficult.

\section{ACKNOWLEDGEMENTS}

We gratefully acknowledge the support of Ing. C. Zaruba, TU Wien and HASYLAB, Hamburg, for providing beam time and experimental support at station L1. This work was supported by the 'European Community Research Infrastructure Action' in the FP6 'Structuring the European Research Area" Program. Author P.M.S. acknowledges financial support within the framework of the research unit 'Sauropod Biology - Evolution of Gigantism' by the Deutsche Forschungsgemeinschaft DFG. This is contribution no. 28 of this research unit.

\section{REFERENCES}

[1] Karkanas, P., Bar-Yosef, O., Goldberg, P., Weiner S., J. Archaeological Sciences, 2000, 27, 915-929.

[2] Reiche, I., Favre-Quattropani, L., Vignaud, C., Bocherens, H., Charlet, L., Menu, M., Meas. Sci. Technol. 2003, 14, 1608-1619.

[3] Pfretzschner, H.-U., N. Jb. Geol. Paläontol. Abh. 2000, 216, 413-432.

[4] Kolodny, Y., Luz, B., Sander, M., Clemens, W.A., Palaeogeogr. Palaeoclimatol. Palaeoecol., 1996, 126, 161-171.

[5] Hubert, J.F., Parish, P.T., Chure, D.J., Prostak, K.S., J. Sediment Res., 1996, 66, 531-547.

[6] Elliott, T.A., Grime, G.W., Nucl. Inst. Methods, 1993, B77, 537-547.

[7] Samoilov, V., Benjamini, Ch., Palaios, 1996, 11, 519-531.

[8] Pfretzschner, H.-U., Vennemann, T.W., Sun, G., Wang, Y.D., Palaeogeogr., Palaeoclimatol., Palaeoecol., 2004, 206, 217-238.

[9] Carvalho, M.L., Marques, A.F., Lima, M.T., Reus, U., Spectrochimica Acta B, 2004, 59, 1251-1257.

[10] Romer, R.L., Geochim. Cosmochim. Acta, 2001, 65, 4201-4213.

[11] Sander, P.M., 2003, 26, 466-488

[12] Janensch, W., Archiv für Biontologie, 1914, 3, 81-110.

[13] Janensch, W., Palaeontographica, 1961, 7, 177-235.

[14] Janensch, W., Palaeontographica, 1950, Suppl. 7, 97-103.

[15] Heinrich, W.-H., Geowissenschaftliche Reihe, 1999, 2, 25-61. 
[16] Janssens, K., Proost, K., Falkenberg, G., Spectrochim. Acta B, 2004, 59 (10-11), 1637-1645.

[17] Vekemans, B., Janssens, K., Vincze, L., Adams, F. and Van Espen, P. X ray Spectrom, 1994, 23, 278-285.

[18] Behrensemeyer, A.K., Palaeobiology, 1978, 4, 150-162.

[19] Bell, L.S., J. Archaeological Science, 1990, 17, 85 - 102.

[20] Parker, R.B., Toots, H., Trace Elements in Bones as Paleobiological Indicators, in: Fossils in the Making, A.K. Behrensmeyer, A.P. Hill (ed.), University of Chicago, Chicago, 1980, 197-207. [21] Ezzo, J.A., J. Anthropological Archaeology, 1994, 13, 1-34.

[22] Rheingold, A.L., Hues, S., Cohen, M.N., J. Chemical Education, 1983, 60, 233-234.

[23] Safont, S., Malgosa, A., Subira, M.E., Gibert, J., Int. J. Osteoarchaeology, 1998, 8, 23-37.

[24] Ferreyro, R., Zoeger, N., Cernohlawek, N., Jokubonis, C., Koch, A., Streli, C., Wobrauschek, P., Sander, P.M., Pyzalla, A., Adv. X-ray Analysis, 2006, 49, 230-235.

[25] Lambert, J.B., Vlasak Simpson, S., Szpunar, C.B., Buikstra, J.E., J. Human Evolution, 1985, $14,477-482$.

[26] Boscher-Barre, N., Trocellier, P., Deschamps, N., Dardenne, C., Blondiaux, J., Buchet, L., J. Trace and Microprobe Techniques, 1992, 10, 77-90.

[27] Reeder, R.J., Grams, J.C., Geochim. Cosmochim. Acta, 1987, 51, 187.

[28] Millard, A.R., Hedges, R.E.M., J. Archaeological Science, 1995, 22, 239-250. 